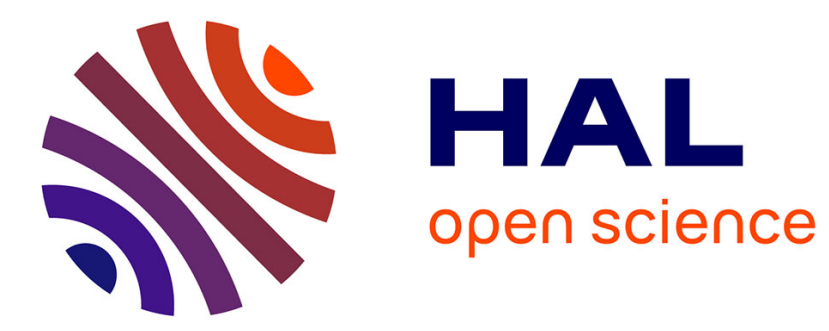

\title{
Excited-state dynamics of the Tm3+ ions and Tm3+ $\rightarrow$ Ho3+ energy transfers in LiYF4
}

\author{
A. Brenier, J. Rubin, R. Moncorge, C. Pedrini
}

\section{To cite this version:}

A. Brenier, J. Rubin, R. Moncorge, C. Pedrini. Excited-state dynamics of the Tm3+ ions and Tm3 $+\rightarrow$ Ho3+ energy transfers in LiYF4. Journal de Physique, 1989, 50 (12), pp.1463-1482. 10.1051/jphys:0198900500120146300 . jpa-00211009

\section{HAL Id: jpa-00211009 https://hal.science/jpa-00211009}

Submitted on 1 Jan 1989

HAL is a multi-disciplinary open access archive for the deposit and dissemination of scientific research documents, whether they are published or not. The documents may come from teaching and research institutions in France or abroad, or from public or private research centers.
L'archive ouverte pluridisciplinaire HAL, est destinée au dépôt et à la diffusion de documents scientifiques de niveau recherche, publiés ou non, émanant des établissements d'enseignement et de recherche français ou étrangers, des laboratoires publics ou privés. 


\title{
Excited-state dynamics of the $\mathrm{Tm}^{3+}$ ions and $\mathrm{Tm}^{3+} \rightarrow \mathrm{Ho}^{3+}$ energy transfers in $\mathrm{LiYF}_{4}$
}

\author{
A. Brenier, J. Rubin, R. Moncorge and C. Pedrini \\ Laboratoire de Physico-Chimie des Matériaux Luminescents (*), Université Lyon I, 43 bd du 11 \\ novembre 1918, 69622 Villeurbanne Cedex, France
}

(Reçu le 20 septembre 1988, révisé le 16 février 1989, accepté le 3 mars 1989)

\begin{abstract}
Résumé. - La dynamique des états excités de $\mathrm{LiYF}_{4}$ faiblement dopé en ions $\mathrm{Tm}^{3+}$ est tout d'abord analysée. Les processus de fluorescence Stokes sont interprétés en tenant compte des nombreuses coïncidences entre les fluorescences émises par les ions $\mathrm{Tm}^{3+}$ et en considérant deux types de sites. Plus compliquée, la dynamique de fluorescence anti-Stokes est décrite seulement très brièvement. Les transferts d'énergie $\mathrm{Tm}^{3+} \rightleftarrows \mathrm{Ho}^{3+}$ sont ensuite étudiés dans des systèmes codopés. Des transferts ${ }^{3} \mathrm{~F}_{4} \rightarrow{ }^{5} \mathrm{I}_{7}$ très efficaces à température ambiante sont rapportés alors que le transfert retour ${ }^{5} \mathrm{I}_{7} \rightarrow{ }^{3} \mathrm{~F}_{4}$ disparaît complètement aux basses températures $(T<200 \mathrm{~K})$. Lorsque les ions $\mathrm{Tm}^{3+}$ sont excités dans leur niveau ${ }^{3} \mathrm{H}_{4}$, on montre que trois voies de désexcitation sont possibles : une désexcitation à l'intérieur d'un même centre $\mathrm{Tm}^{3+}$, une relaxation croisée entre ions $\mathrm{Tm}^{3+}$ adjacents du type ${ }^{3} \mathrm{H}_{4},{ }^{3} \mathrm{H}_{6} \rightarrow{ }^{3} \mathrm{~F}_{4},{ }^{3} \mathrm{~F}_{4}$ et un transfert direct $\mathrm{Tm}^{3+} \rightarrow \mathrm{Ho}^{3+}$. Le premier mécanisme est très faible et les deux autres sont en compétition, le dernier dominant largement à haute concentration en ions $\mathrm{Ho}^{3+}$.
\end{abstract}

\begin{abstract}
The excited-state dynamics of the $\mathrm{Tm}^{3+}$ ions in a singly doped crystal of $\mathrm{LiYF}_{4}$ is analysed. The Stokes fluorescence processes are interpreted by taking into account the numerous coincidences between the fluorescences emitted by the $\mathrm{Tm}^{3+}$ ions and by considering two kinds of sites. The anti-Stokes fluorescence dynamics which are more complicated are only briefly described. The $\mathrm{Tm}^{3+} \rightarrow \mathrm{Ho}^{3+}$ energy transfers are then analysed in codoped systems. Very efficient ${ }^{3} \mathrm{~F}_{4} \rightarrow{ }^{5} \mathrm{I}_{7}$ energy transfers are reported at room temperature whereas the ${ }^{5} \mathrm{I}_{7} \rightarrow{ }^{3} \mathrm{~F}_{4}$ back-transfer is completely quenched at low temperatures $(T<200 \mathrm{~K})$. When the $\mathrm{Tm}^{3+}$ ions are excited in their ${ }^{3} \mathrm{H}_{4}$ level, it is shown that three channels of de-excitation have to be considered : a $\mathrm{Tm}^{3+}$ intra-center de-excitation, a cross-relaxation process between adjacent $\mathrm{Tm}^{3+}$ ions of type ${ }^{3} \mathrm{H}_{4},{ }^{3} \mathrm{H}_{6} \rightarrow{ }^{3} \mathrm{~F}_{4},{ }^{3} \mathrm{~F}_{4}$ and a direct $\mathrm{Tm}^{3+} \rightarrow \mathrm{Ho}^{3+}$ energy transfer. The former mechanism is very weak while the other two compete, the latter being largely dominant at high $\mathrm{Ho}^{3+}$ concentrations.
\end{abstract}

\section{Introduction.}

The $2 \mu \mathrm{m}$ infra-red laser emission of $\mathrm{Ho}^{3+}$ activator ions imbedded in single crystals is usually sensitized by $\mathrm{Er}^{3+}$ and (or) $\mathrm{Tm}^{3+}$ ions. This is the case of the triply doped laser system $\alpha \beta \mathrm{LiYF}_{4}: \mathrm{Ho}^{3+}$ in which both the $\mathrm{Er}^{3+}$ and the $\mathrm{Tm}^{3+}$ ions are sensitizers [1] ; it also

(*) Unité associée au CNRS, $\mathrm{n}^{\circ} 442$. 
applies to the codoped system $\mathrm{LiYF}_{4}: \mathrm{Tm}^{3+}, \mathrm{Ho}^{3+}$. The first one operates by pumping the material with C.W. or pulsed broad-band lamp sources [2]. The codoped system is proposed as a mid infrared diode-pumped solid state laser [3] because recent progress in this field makes the latter scheme an attractive alternative to lamp-pumped operation and also because a very good spectral match exists between the $\mathrm{Ga} \mathrm{Al} \mathrm{As} \mathrm{diode} \mathrm{emission} \mathrm{and} \mathrm{the} \mathrm{Tm}^{3+}$ absorption near $795 \mathrm{~nm}$.

In a previous study, we have already considered the sensitization of the $2 \mu \mathrm{m} \mathrm{Ho}^{3+}$ emission by the $\mathrm{Er}^{3+}$ ions, in $\mathrm{LiYF}_{4}$ single crystals [4] and in fluoride glasses [5], and have described the $\mathrm{Er}^{3+} \rightarrow \mathrm{Ho}^{3+}$ energy transfers by using rate equations. The $\mathrm{Er}^{3+}$ ions were excited in the visible and the infrared domains and we measured the relative contribution of each channel of deexcitation of the ${ }^{5} \mathrm{I}_{7}$ emitting level of $\mathrm{Ho}^{3+}$ as a function of the $\mathrm{Er}^{3+}$ excitation level. The results show that this sensitization is particularly interesting in the case of pumping in the visible region, for example with a broad-band flash lamp or the $532 \mathrm{~nm}$ radiation of a frequency doubled YAG : $\mathrm{Nd}^{3+}$ laser.

The complexity of fluorescence dynamics in the rare earth doped materials is now well known. In particular, the occurrence of non-linear processes such as up-conversion and crossrelaxation energy transfers is well established [6-9] and excellent review articles have been devoted to this field in the past years $[10,11]$. However, the relative importance of the various processes in the relaxation mechanisms is not very often considered, and what applies for an ion in a given host matrix can be wrong for the same ion in another host. Then each case still needs to be carefully analysed.

As a matter of fact, this paper is dedicated to a detailed study of the excited-state dynamics of the $\mathrm{Tm}^{3+}$ and $\mathrm{Ho}^{3+}$ ions in $\mathrm{LiYF}_{4}$, in order to identify and evaluate the main relaxation mechanisms and to check the assumptions made in the past. Our method of analysis is similar to that used in the above studies [4,5]. The experimental data and the interpretations of the fluorescence kinetics for a $1 \% \mathrm{Tm}^{3+}$ singly doped compound are presented in section 3 . The $\mathrm{Tm}^{3+} \rightarrow \mathrm{Ho}^{3+}$ energy transfer mechanisms are then considered in codoped compounds of $\mathrm{LiYF}_{4}$ containing $7 \% \mathrm{Tm}^{3+}$ and $x \% \mathrm{Ho}^{3+}(x=0.5,2$ and 5$)$ and the results are presented in section 4. Particular attention is adressed to the analysis and the interpretation of the $\mathrm{Ho}^{3+}$ concentration and the temperature dependences of the fluorescence dynamics. A summary of the results and some concluding remarks are added in section 5.

\section{Experimental techniques.}

The single crystals were grown using the Czochralsky method by Henry at the L.E.T.I. (Grenoble, France). The optical excitation of the samples was made by using the same pulsed YAG : $\mathrm{Nd}^{3+}$ pumped dye laser as that described in one of our articles dedicated to the study of the $\mathrm{Er}^{3+}$ fluorescence dynamics in $\mathrm{LiYF}_{4}$ [12]. We also used a home made pulsed YAG : $\mathrm{Nd}^{3+}$ pumped $\mathrm{Al}_{2} \mathrm{O}_{3}: \mathrm{Ti}^{3+}$ solid-state laser tunable in the $680-980 \mathrm{~nm}$ region and delivering up to $30 \mathrm{~mJ} /$ pulse [13]. The optical techniques used in the fluorescence detection and analysis in the infra-red range and more especially the recording of the lifetime data, are discussed in reference [5]. The fluorescence time constants are measured within $10 \%$ depending on the intensity of the signals and on the theoretical treatment of the data. The absorption measurements were made using a CARY UV - visible - NIR spectrophotometer model 2300, spanning the wavelength range from 185 to $3152 \mathrm{~nm}$.

\section{Excited state dynamics of the $\mathrm{Tm}^{3+}$ ions in $\mathrm{LiYF}_{4}: 1 \% \mathrm{Tm}^{3+}$.}

3.1 SPECTRAL ANALYSIS. - The total absorption spectrum of the $\mathrm{Tm}^{3+}$ ion in $\mathrm{LiYF}_{4}$ at room temperature is shown in figure 1. The assignment of the various peaks, as indicated in this 


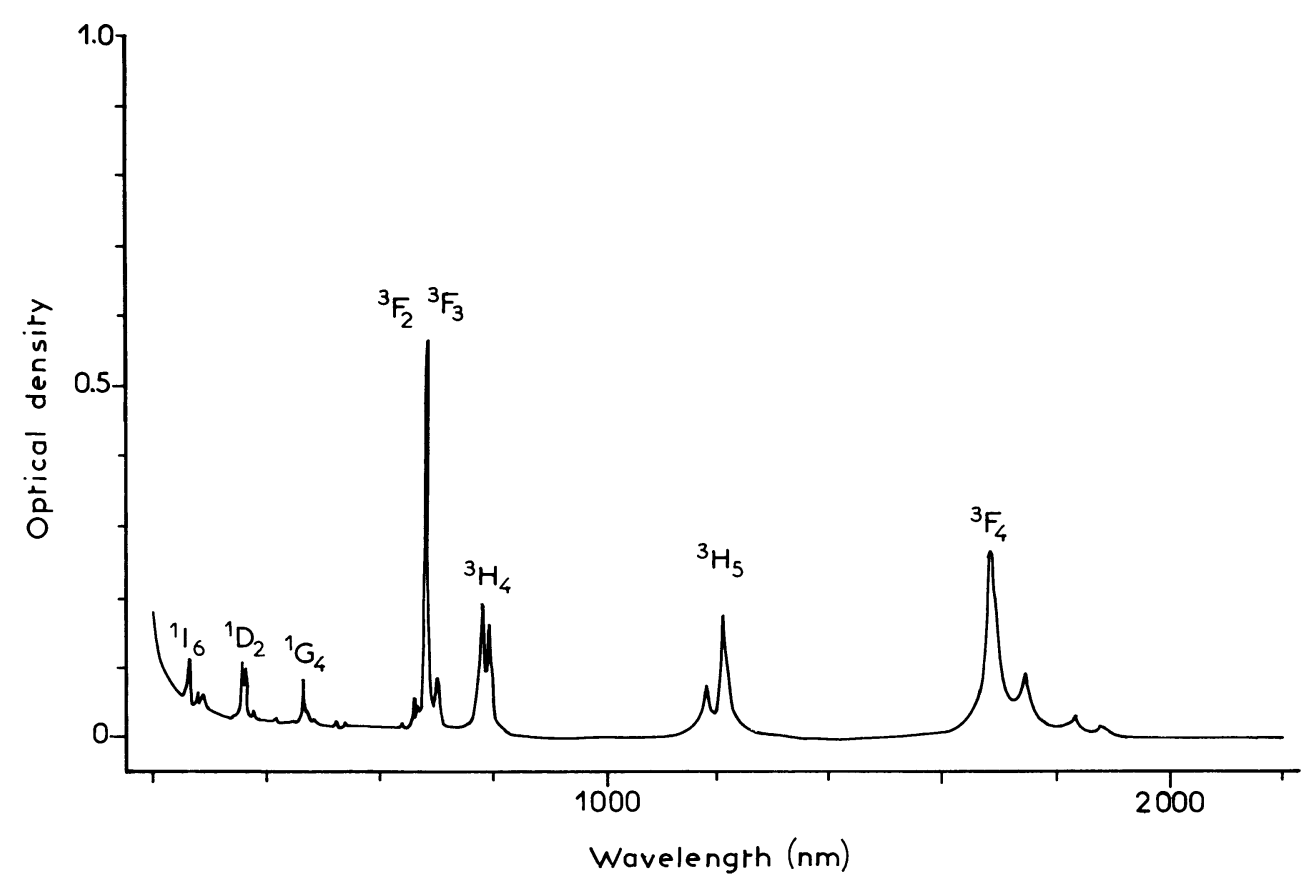

Fig. 1. - Absorption spectrum of the $\mathrm{Tm}^{3+}$ ion in $\mathrm{LiYF}_{4}$ at room temperature $\left(\mathrm{Tm}^{3+}\right.$ concentration : $1 \%$; sample thickness : $5.1 \mathrm{~mm}$ ).

figure, leads to the energy level scheme represented in figure 2 . We have reported all the possible emission transitions which can occur between 4000 and $25000 \mathrm{~cm}^{-1}$ as a function of their energy. It can be seen that a large number of fluorescences coincide in energy, so that they have to be taken into account in the following.

3.2 STOKES FLUORESCENCE DYNAMICS. - This dynamics describes the downward relaxation following the excitation of a given state. Each of the energy levels in the visible and infrared domains has been excited selectively. The excitation of most of these levels (the lowest ones) leads to simple relaxation processes while the excitation of the ${ }^{1} \mathrm{G}_{4}$ level gives rise to more complex phenomena. Therefore these two cases will be considered separately.

3.2.1 Infrared and red excitations. - The excitation of the ${ }^{3} \mathrm{~F}_{4}$ state gives rise predominantly to the ${ }^{3} \mathrm{~F}_{4} \rightarrow{ }^{3} \mathrm{H}_{6}$ emission transition near $1.8 \mu \mathrm{m}$. The fluorescence decay is exponential, with a time-constant of $16 \mathrm{~ms}$, the lifetime of the ${ }^{3} \mathrm{~F}_{4}$ level.

When the $\mathrm{Tm}^{3+}$ ions are excited in their ${ }^{3} \mathrm{H}_{5}$ state, no fluorescence of this level could have been detected. The ${ }^{3} \mathrm{~F}_{4} \rightarrow{ }^{3} \mathrm{H}_{6}$ radiative transition, however, is easily observed and the fluorescence decay mode is the same as in the case of direct excitation of the ${ }^{3} \mathrm{~F}_{4}$ level. The absence of any measurable risetime (the response of our InSb detector was of the order of $0.5 \mu \mathrm{s}$ ) means that the lifetime of the ${ }^{3} \mathrm{H}_{5}$ state is short (likely $<0.5 \mu \mathrm{s}$ ), which can be attributed to the small energy gap and the very probable non-radiative relaxation between the ${ }^{3} \mathrm{H}_{5}$ and the ${ }^{3} \mathrm{~F}_{4}$ levels.

The excitation of the ${ }^{3} \mathrm{H}_{4}$ level gives rise to a ${ }^{3} \mathrm{H}_{4} \rightarrow{ }^{3} \mathrm{H}_{6}$ fluorescence transition between 760 and $830 \mathrm{~nm}$. Its decay is exponential with a time-constant of $1.45 \mathrm{~ms}$, the lifetime of the 


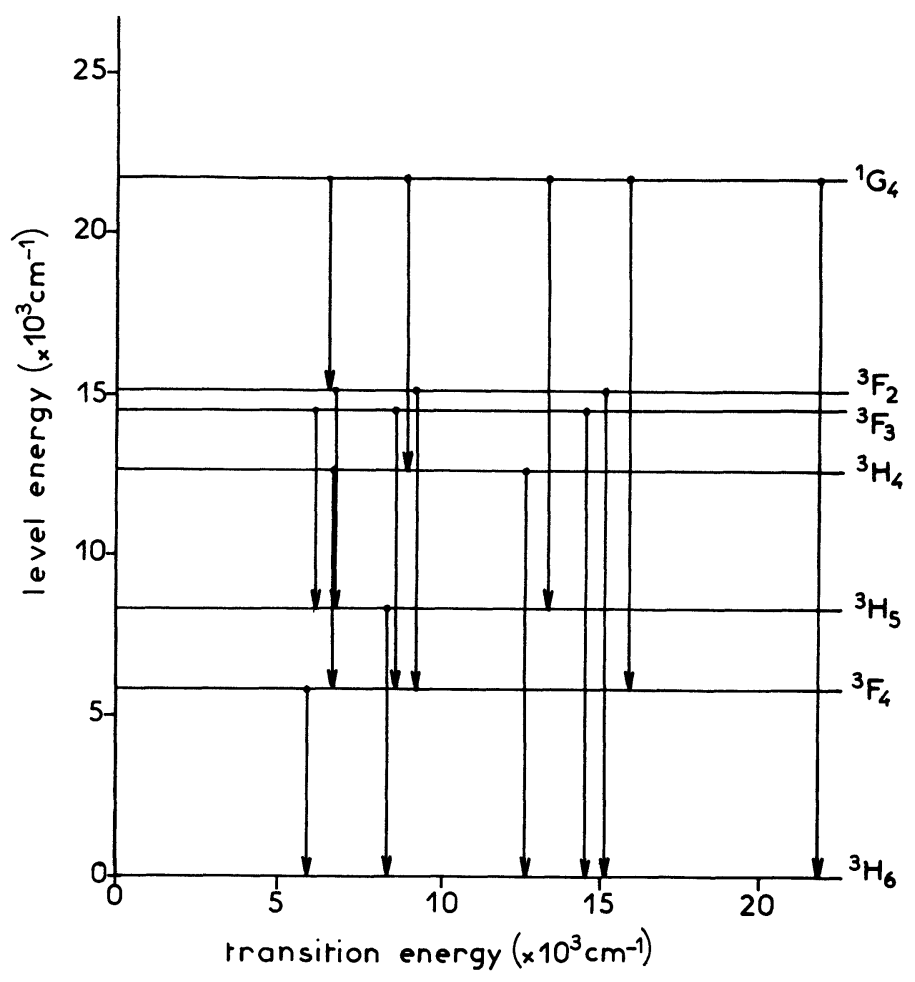

Fig. 2. - Energy level scheme of the $\mathrm{Tm}^{3+}$ ion and main emission transitions.

${ }^{3} \mathrm{H}_{4}$ level. The fluorescence of the ${ }^{3} \mathrm{~F}_{4} \rightarrow{ }^{3} \mathrm{H}_{6}$ transition is also detected and its decay mode (Fig. 3) is well described by the expression :

$$
I(t) \propto \exp (-t / 16)-\exp (-t / 1.45)
$$

with time $t$ in $\mathrm{ms}$.

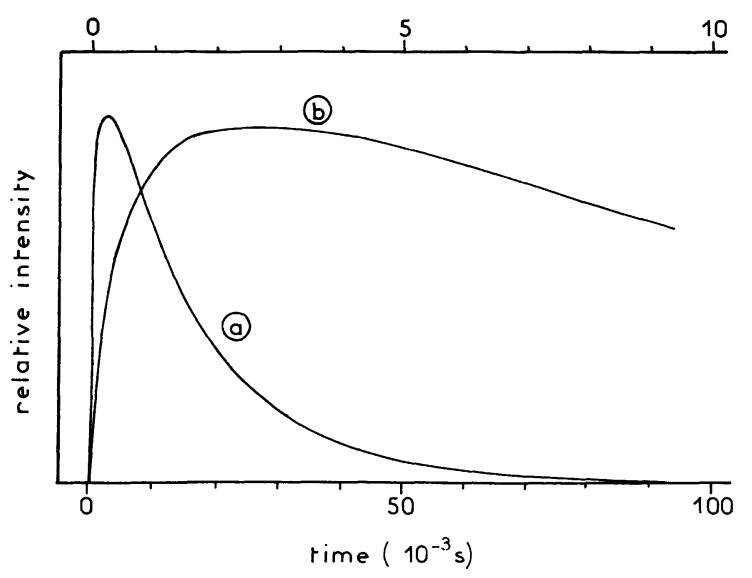

Fig. 3. - Time-dependence of the ${ }^{3} \mathrm{~F}_{4} \rightarrow{ }^{3} \mathrm{H}_{6}$ infrared fluorescence after ${ }^{3} \mathrm{H}_{4}$ excitation in $\mathrm{LiYF}_{4}: 1 \%$ $\mathrm{Tm}^{3+}$. Curve a : lower scale ; curve b : upper scale. 
The built-up reflects the feeding of the ${ }^{3} \mathrm{~F}_{4}$ level by the ${ }^{3} \mathrm{H}_{4}$ level and the decay the lifetime of the ${ }^{3} \mathrm{~F}_{4}$ level. Thus this time dependence is indicative of a very efficient ${ }^{3} \mathrm{H}_{4} \rightarrow{ }^{3} \mathrm{~F}_{4}$ energy relaxation. This relaxation process can occur via level ${ }^{3} \mathrm{H}_{5}$ and/or directly, in which case it could occur with the participation of one and/or two ions transferring their energy from one to the other in a cross-relaxation process of type

$$
{ }^{3} \mathrm{H}_{4} \text { (ion } 1 \text { ), }{ }^{3} \mathrm{H}_{6} \text { (ion 2) } \rightarrow{ }^{3} \mathrm{~F}_{4} \text { (ion } 1 \text { ), }{ }^{3} \mathrm{~F}_{4} \text { (ion 2). }
$$

This is suggested by the reduced lifetime of $1.45 \mathrm{~ms}$ of state ${ }^{3} \mathrm{H}_{4}$ in our $1 \%$ $\mathrm{Tm}^{3+}$ compound compared to that found in weaker doped materials $[14,15]$.

The red excitation of the ${ }^{3} \mathrm{~F}_{3}$ level gives rise to the ${ }^{3} \mathrm{H}_{4} \rightarrow{ }^{3} \mathrm{H}_{6}$ emission the decay mode of which is exponential with a time-constant of $1.45 \mathrm{~ms}$. The absence of built-up is due to the short lifetime of the ${ }^{3} \mathrm{~F}_{3}$ level $(<\mu \mathrm{s})$, which is explained by the small ${ }^{3} \mathrm{~F}_{3}{ }^{3} \mathrm{H}_{4}$ energy difference. The ${ }^{3} \mathrm{H}_{4}$ level again de-excites itself in favour of the ${ }^{3} \mathrm{H}_{5},{ }^{3} \mathrm{~F}_{4}$ and ${ }^{3} \mathrm{H}_{6}$ lower states according to the same mechanism as described before in case of ${ }^{3} \mathrm{H}_{4}$ excitation. The main role played by the ${ }^{3} \mathrm{~F}_{3}$ level is to quickly transmit the energy to the ${ }^{3} \mathrm{H}_{4}$ state. However it will be seen in part 3.3 of this section that it may also induce more complex phenomena.

3.3.2 Blue excitation of the ${ }^{1} \mathrm{G}_{4}$ level. - This excitation leads to several emissions which are considered in succession.

3.2.2.1 ${ }^{1} \mathrm{G}_{4} \rightarrow{ }^{3} \mathrm{H}_{6}$ blue-green fluorescence transition. - The fluorescence decays measured between 460 and $490 \mathrm{~nm}$ are not exponential and are described by the expression :

$$
I(t) \propto 1.5 \exp (-t / 0.120)+\exp (-t / 0.570)
$$

with time $t$ in ms.

3.2.2.2 ${ }^{1} \mathrm{G}_{4} \rightarrow{ }^{3} \mathrm{~F}_{4}$ and ${ }^{3} \mathrm{~F}_{2},{ }^{3} \mathrm{~F}_{3} \rightarrow{ }^{3} \mathrm{H}_{6}$ red fluorescence transitions. - This red emission spectrum ranges between 620 and $680 \mathrm{~nm}$. The decay modes are similar to the blue-green fluorescence ones previously obtained. They are assigned to the ${ }^{1} G_{4} \rightarrow{ }^{3} F_{4}$ transition. That means that the contribution of the red emission originating from the ${ }^{3} F_{2}$ and ${ }^{3} F_{3}$ levels is very weak because of a fast multiphonon relaxation ${ }^{3} \mathrm{~F}_{2} \rightarrow{ }^{3} \mathrm{~F}_{3} \rightarrow{ }^{3} \mathrm{H}_{4}$.

3.2.2.3 ${ }^{1} \mathrm{G}_{4} \rightarrow{ }^{3} \mathrm{H}_{5}$ and ${ }^{3} \mathrm{H}_{4} \rightarrow{ }^{3} \mathrm{H}_{6}$ near infrared fluorescence transitions. - These fluorescences overlap over a wide spectral range from 760 to $830 \mathrm{~nm}$. The short wavelength fluorescence between about 760 and $780 \mathrm{~nm}$ seems to be dominated by the ${ }^{1} \mathrm{G}_{4}$ emission and its decay is represented in figure $4 \mathrm{a}$. On the other hand the long wavelength fluorescence $(\lambda>790 \mathrm{~nm})$ seems to be dominated by the ${ }^{3} \mathrm{H}_{4}$ emission and its decay mode includes a well pronounced built-up at short times (Fig. 4b). However the interpretation of these data is not straightforward and requires to write some appropriate rate equations.

The intensity of each of the two ${ }^{1} \mathrm{G}_{4} \rightarrow{ }^{3} \mathrm{H}_{5}$ and ${ }^{3} \mathrm{H}_{4} \rightarrow{ }^{3} \mathrm{H}_{6}$ infrared emissions is proportional to the population of the ${ }^{1} \mathrm{G}_{4}$ and of the ${ }^{3} \mathrm{H}_{4}$ emitting state, respectively. According to equation (2) the population $N$ of the ${ }^{1} \mathrm{G}_{4}$ state transforms like :

$$
N=\frac{N_{0}}{2.5}[1.5 \exp (-t / 0.120)+\exp (-t / 0.570)] \text {. }
$$

This time evolution is represented by the curve a of figure 5 .

The population $N^{\prime}$ of the ${ }^{3} \mathrm{H}_{4}$ level varies according to the equation :

$$
\dot{N}^{\prime}=-\frac{N^{\prime}}{1.45}+A N(t)
$$




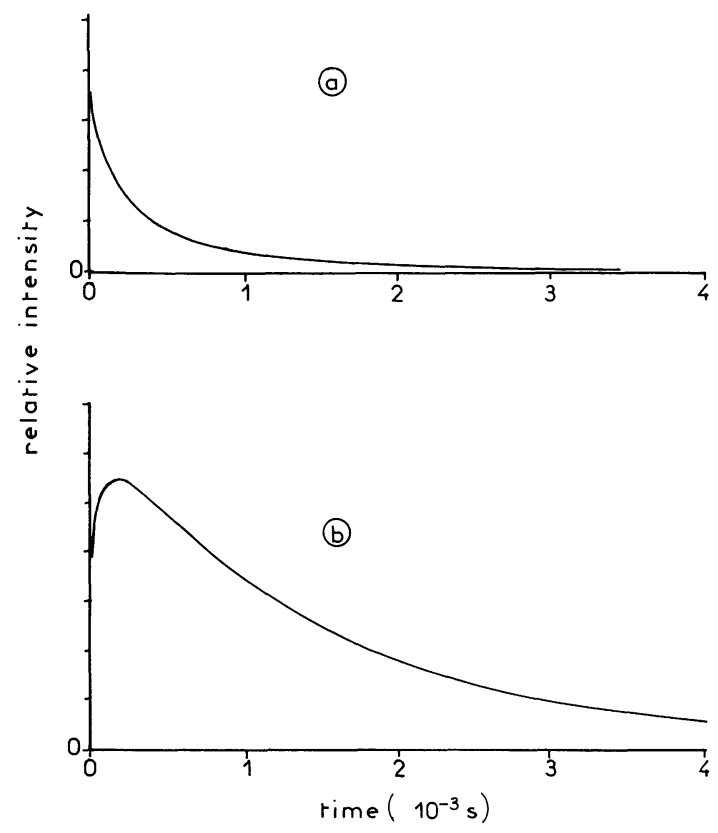

Fig. 4. - Time-dependence of the ${ }^{1} \mathrm{G}_{4} \rightarrow{ }^{3} \mathrm{H}_{5}$ and/or ${ }^{3} \mathrm{H}_{4} \rightarrow{ }^{3} \mathrm{H}_{6}$ fluorescence infrared fluorescences after ${ }^{1} \mathrm{G}_{4}$ excitation in $\mathrm{LiYF}_{4}: 1 \% \mathrm{Tm}^{3+}$. Curve a : emission at $770 \mathrm{~nm}$; curve b : emission at $815 \mathrm{~nm}$.

where $1.45 \mathrm{~ms}$ is the lifetime of the ${ }^{3} \mathrm{H}_{4}$ level and $A$ represents the total ${ }^{1} \mathrm{G}_{4} \rightarrow{ }^{3} \mathrm{H}_{4}$ transition probability (direct and via ${ }^{3} \mathrm{~F}_{2},{ }^{3} \mathrm{~F}_{3}$ ). The solution of (4) takes the form given by the curve $\mathrm{b}$ of figure 5 .

Because of the spectral overlap the observed signal should be the sum of the two emissions

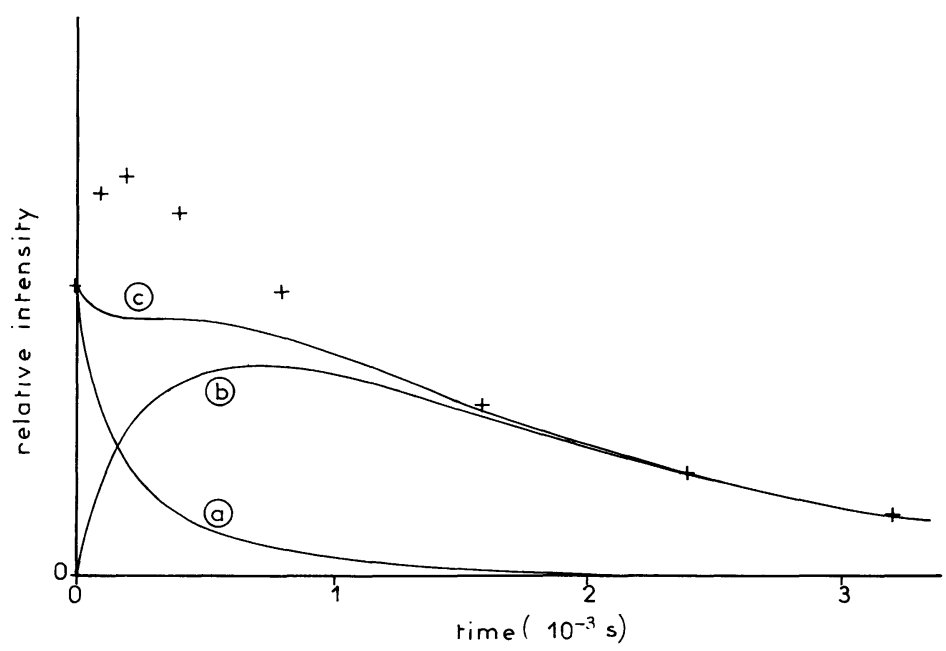

Fig. 5. - Theoretical curves describing the ${ }^{1} \mathrm{G}_{4} \rightarrow{ }^{3} \mathrm{H}_{5}$ fluorescence decay (curve a), the ${ }^{3} \mathrm{H}_{4} \rightarrow{ }^{3} \mathrm{H}_{6}$ fluorescence decay (curve b) and the linear combination (curve c) which gives the best fit to the experimental data $(+)$. 
and its temporal dependence should depend on their relative intensities, therefore on the fluorescence wavelength considered.

We have tried to fit the corresponding experimental data by a linear combination of the $N(t)$ and $N^{\prime}(t)$ functions. For example at $815 \mathrm{~nm}$ the best fit is represented by the curve c of figure 5. This bad fit proves that the model is unable to describe the observed short-time behaviour $(0.120 \mathrm{~ms})$, and therefore is not convenient to explain the dynamics correctly. Another model based on the former can be proposed by dissociating the origins of the two exponential terms of the decay curve of the ${ }^{1} \mathrm{G}_{4}$ emission. When a $\mathrm{Tm}^{3+}$ ion (1) is excited in the ${ }^{1} \mathrm{G}_{4}$ state it can decay (radiatively or non radiatively) on the lower states ${ }^{3} \mathrm{H}_{5}$, ${ }^{3} \mathrm{~F}_{4},{ }^{3} \mathrm{H}_{6}$ with a probability of $10^{3} / 0.570 \mathrm{~s}^{-1}$. It can also decay with the aid of another $\mathrm{Tm}^{3}+$ ion (2) according to the cross-relaxation type energy transfer :

$$
\left.\left.\left.{ }^{1} \mathrm{G}_{4} \text { (ion } 1\right),{ }^{3} \mathrm{H}_{6} \text { (ion } 2\right) \rightarrow{ }^{3} \mathrm{~F}_{2} \text { (ion } 1\right),{ }^{3} \mathrm{~F}_{4} \text { (ion 2) . }
$$

Figure 6 shows the $\mathrm{LiYF}_{4}$ crystal structure and the positions of the possible nearest neighbours which can be involved in the transfer. Numerical value of the nearest-neighbour distances $r$ are given in table $\mathrm{I}$.

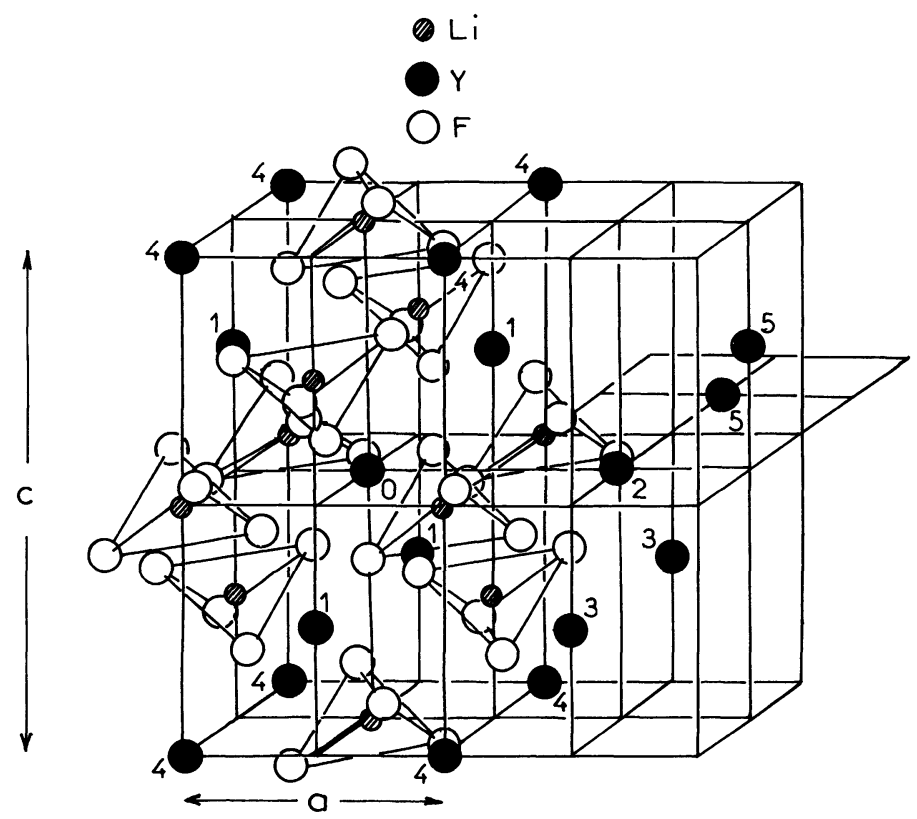

Fig. 6. $-\mathrm{LiYF}_{4}$ crystal structure and nearest neighbours of a given $\mathrm{Y}^{3+}$ ion (0).

By simplification, two types of sites may be considered : either quasi isolated $\mathrm{Tm}^{3+}$ ions (1) or $\mathrm{Tm}^{3+}$ ions (1) with other $\mathrm{Tm}^{3+}$ ions (2) in their vicinity, the latter corresponding to the overall transfer probability :

$$
k=\frac{10^{3}}{0.120}-\frac{10^{3}}{0.570} \sim 6600 \mathrm{~s}^{-1} .
$$

The mechanism for these two sites are shown in figure 7. 
Table I.

\begin{tabular}{ccc}
\hline Neighbours & $\begin{array}{c}\text { Distance from } \\
\text { the reference } \\
\text { ion }(\AA)\end{array}$ & $\begin{array}{c}\text { Number of } \\
\text { equivalent } \\
\text { neighbours }\end{array}$ \\
\hline 1st & 3.72 & 4 \\
2nd & 5.16 & 4 \\
3rd & 6.37 & 4 \\
3rd & 6.37 & 4 \\
4th & 6.48 & 8 \\
5th & 7.30 & 4 \\
6th & 8.19 & 4 \\
\hline
\end{tabular}

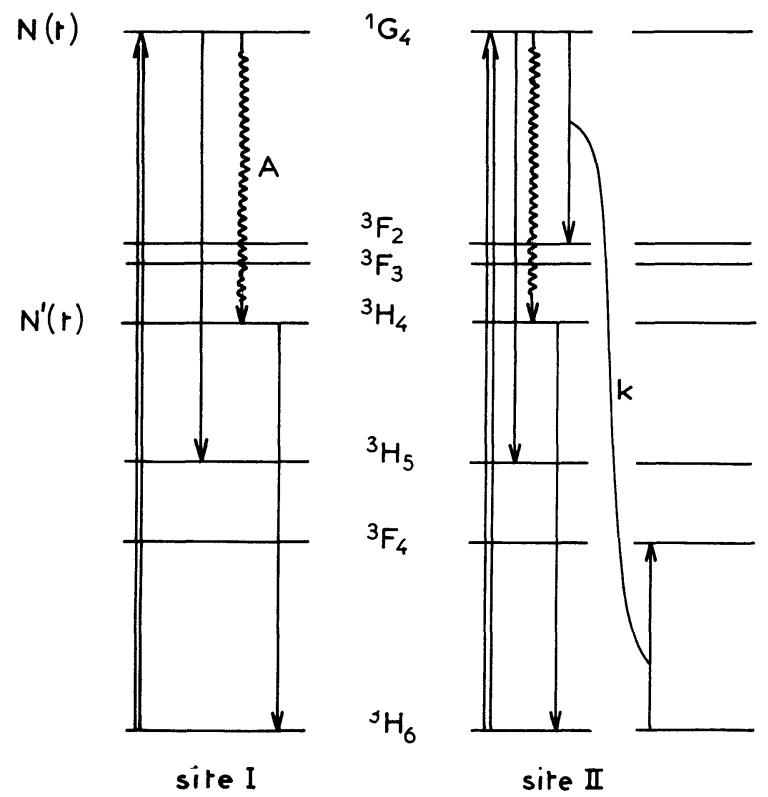

Fig. 7. $-{ }^{1} \mathrm{G}_{4} \rightarrow{ }^{3} \mathrm{H}_{5}$ and ${ }^{3} \mathrm{H}_{4} \rightarrow{ }^{3} \mathrm{H}_{6}$ infrared fluorescence mechanisms for $\mathrm{Tm}^{3+}$ ions occupying sites of type $\mathrm{I}$ and type II in $\mathrm{LiYF}_{4}$.

Site I. - The ${ }^{1} \mathrm{G}_{4}$ fluorescence decays exponentially with a time-constant of $0.570 \mathrm{~ms}$, so that :

$$
N_{\text {I }}=N_{0} \exp (-t / 0.570)
$$

The rate equation describing the time dependence of the ${ }^{3} \mathrm{H}_{4}$ population of the sites I then transforms like :

$$
\dot{N}_{\mathrm{I}}^{\prime}=-\frac{N_{\mathrm{I}}^{\prime}}{1.45}+\frac{\alpha}{0.570} N_{0} \exp (-t / 0.570)
$$


where $\alpha$ is the fractional part of the ${ }^{1} \mathrm{G}_{4}$ de-excitation probability which ends directly or via ${ }^{3} \mathrm{~F}_{2}$ and ${ }^{3} \mathrm{~F}_{3}$ on state ${ }^{3} \mathrm{H}_{4}$. $\alpha$ is considered as a fitting parameter. The solution of equation (7) is :

$$
N_{\mathrm{I}}^{\prime}(t)=\frac{1.45 \times 0.570}{1.45-0.570} \times \frac{\alpha}{0.570} N_{0}[\exp (-t / 1.45)-\exp (-t / 0.570)]
$$

Site II. - The ${ }^{1} \mathrm{G}_{4}$ fluorescence decays with the time-constant of $0.120 \mathrm{~ms}$ as :

so,

$$
\begin{aligned}
& N_{\text {II }}=N_{0} \times 1.5 \exp \left[-\left(\frac{1}{0.570}+10^{-3} k\right) t\right] \\
& N_{\text {II }}=N_{0} \times 1.5 \exp (-t / 0.120)
\end{aligned}
$$

The cross relaxation mechanism feeds the ${ }^{3} \mathrm{H}_{4}$ level via the strong ${ }^{3} \mathrm{~F}_{2} \rightarrow{ }^{3} \mathrm{~F}_{3} \rightarrow{ }^{3} \mathrm{H}_{4}$ multiphonon relaxations, so the rate equation for the ${ }^{3} \mathrm{H}_{4}$ population transforms like :

$$
\dot{N}_{\text {II }}^{\prime}=-\frac{N_{\text {II }}^{\prime}}{1.45}+\left(\frac{\alpha}{0.570}+10^{-3} k\right) N_{0} \times 1.5 \exp (-t / 0.120)
$$

which gives the solution :

$N_{\mathrm{II}}^{\prime}(t)=\frac{1.45 \times 0.120}{1.45-0.120} \times\left(\frac{\alpha}{0.570}+10^{-3} k\right) N_{0} \times 1.5[\exp (-t / 1.45)-\exp (-t / 0.120)]$

The overall intensity of the ${ }^{3} \mathrm{H}_{4}$ fluorescence then is proportional to $N_{\mathrm{I}}^{\prime}(t)+N_{\mathrm{II}}^{\prime}(t)$, the best fit to the experimental points being represented by the curve $b$ of figure 8 . In agreement with these points a shorter built-up than that predicted by the previous model is obtained so that a linear combination of both the ${ }^{3} \mathrm{H}_{4}$ and ${ }^{1} \mathrm{G}_{4}$ emissions reproduces very well the experimental results (curve c, Fig. 8).

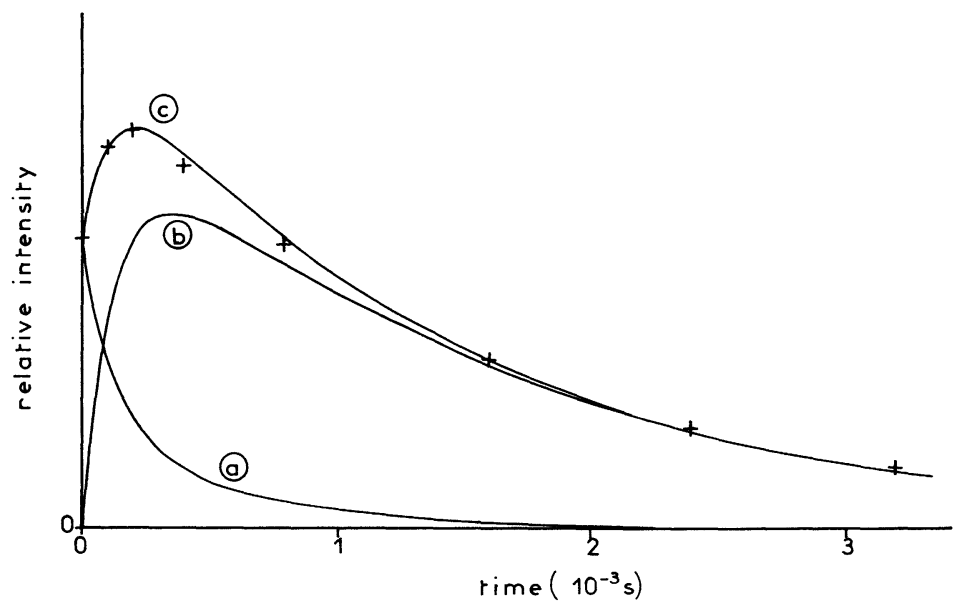

Fig. 8. - Theoretical curves giving the ${ }^{1} \mathrm{G}_{4} \rightarrow{ }^{3} \mathrm{H}_{5}$ fluorescence decay of the $\mathrm{Tm}^{3+}$ ions in sites $\mathrm{I}$ and sites II (curve a), the best fit to the ${ }^{3} \mathrm{H}_{4} \rightarrow{ }^{3} \mathrm{H}_{6}$ fluorescence decay (curve b) and the linear combination of the ${ }^{1} \mathrm{G}_{4}$ and ${ }^{3} \mathrm{H}_{4}$ fluorescences (curve c).

3.2.2.4 ${ }^{3} \mathrm{~F}_{4} \rightarrow{ }^{3} \mathrm{H}_{6}$ infrared fluorescence transitions. - The present model should be able to describe the time dependence of the ${ }^{3} \mathrm{~F}_{4} \rightarrow{ }^{3} \mathrm{H}_{6}$ fluorescence. The experimental data are 
represented in figure 9. First one observes a short build-up $(\tau \sim 0.1 \mathrm{~ms})$, then a longer one and finally a long decay with a $16 \mathrm{~ms}$ time constant. If we use the rate equation

$$
\dot{N}^{\prime \prime}=-\frac{N^{\prime \prime}}{16}+\beta N_{\mathrm{II}}^{\prime}(t)
$$

associated with the de-excitation channel ${ }^{1} \mathrm{G}_{4} \rightarrow{ }^{3} \mathrm{H}_{4} \rightarrow{ }^{3} \mathrm{~F}_{4}$ of the $\mathrm{Tm}^{3+}$ ions in sites II ( $N^{\prime \prime}$ stands for the ${ }^{3} \mathrm{~F}_{4}$ population) to fit the experimental data, one obtains a longer risetime than the one observed (Fig. 9, curve a). On the other hand, if we only consider the direct deexcitation channel ${ }^{1} \mathrm{G}_{4} \rightarrow{ }^{3} \mathrm{~F}_{4}$ of the $\mathrm{Tm}^{3+}$ in sites II described by the equation :

$$
\dot{N}^{\prime \prime}=-\frac{N^{\prime \prime}}{16}+\gamma \exp (-t / 0.120),
$$

the rapid risetime is well reproduced but not the longer one (Fig. 9, curve b). This deexcitation channel can be attributed to the cross-relaxation type energy transfer :

$$
{ }^{1} \mathrm{G}_{4} \text { (ion } 1 \text { ), }{ }^{3} \mathrm{H}_{6} \text { (ion 2) } \rightarrow{ }^{3} \mathrm{~F}_{2} \text { (ion } 1 \text { ), }{ }^{3} \mathrm{~F}_{4} \text { (ion 2) }
$$

a transfer process which gives the same result as that considered above (see Fig. 7).

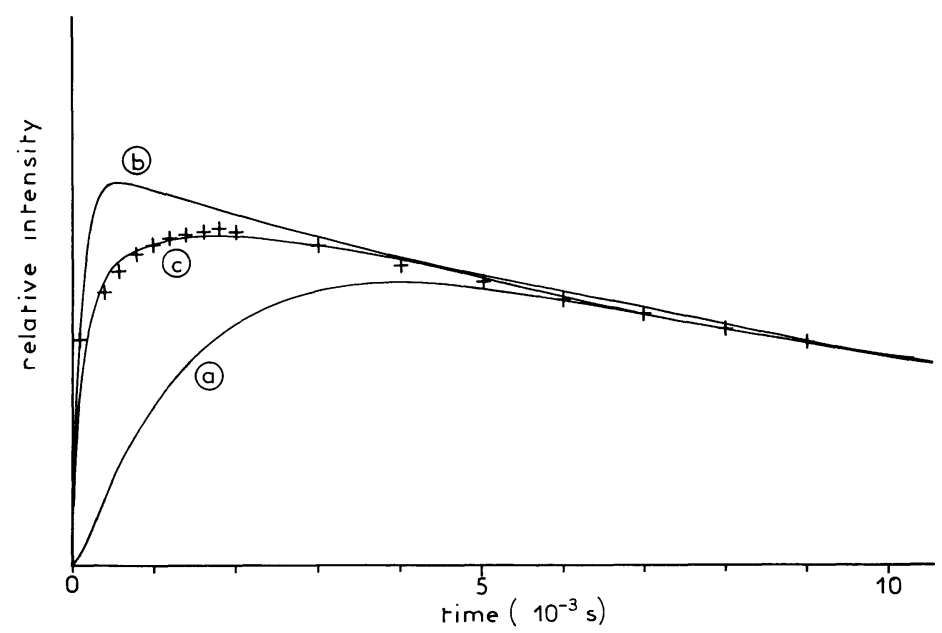

Fig. 9. - Theoretical curves describing the ${ }^{3} \mathrm{~F}_{4} \rightarrow{ }^{3} \mathrm{H}_{6}$ infrared fluorescence decay of $\mathrm{Tm}^{3+}$ ions in sites II.

Naturally, the right time dependence of the ${ }^{3} \mathrm{~F}_{4}$ fluorescence has been found by considering both the direct and the indirect de-excitation channels of the $\mathrm{Tm}^{3+}$ ions in sites II and by solving the rate equation :

$$
\dot{N}^{\prime \prime}=-\frac{N^{\prime \prime}}{16}+\gamma \exp (-t / 0.120)+\beta N_{\text {II }}^{\prime} .
$$

The agreement shown in the curve $\mathrm{c}$ of figure 9 between the model and the experimental data is indeed very good. The cross-relaxation mechanism resulting in the direct de-excitation channel ${ }^{1} \mathrm{G}_{4} \rightarrow{ }^{3} \mathrm{~F}_{4}$ thus is clearly evidenced.

3.3 UP-CONVERSION PROCESSES AND EXCITATION OF PARTICULAR SITES. - These complex phenomena give rise to much weaker emissions than those analysed in the previous 
subsections and it is why their influence on the Stokes fluorescence dynamics is negligible and was not considered.

However, these processes actually occur and this paragraph is devoted to their study. Their complexity does not always allow to find a clear interpretation of the phenomena so that this part must be considered more as a descriptive study than as an accurate analysis of the experimental results.

3.3.1 760-830 $\mathrm{nm}$ infrared emission. - We have seen that this fluorescence originates from the ${ }^{3} \mathrm{H}_{4}$ and ${ }^{1} \mathrm{G}_{4}$ levels. It can be observed by exciting the $\mathrm{Tm}^{3+}$ ions in the ${ }^{3} \mathrm{H}_{5}$ state thus resulting from an up-conversion phenomenon. Its time-dependence is peculiar, however : the decay, at $\lambda=793 \mathrm{~nm}$, shows two short components (2 and $25 \mu \mathrm{s}$ ) and a long one (1.6 ms) without any evidence of risetime. The long component reflects the lifetime of the ${ }^{3} \mathrm{H}_{4}$ level and the short components are probably due to the de-excitation of the ${ }^{1} \mathrm{G}_{4}$ state. We have seen that the lifetime of this level depends on the site occupied by the emitting $\mathrm{Tm}^{3}+$ ions. In case of ${ }^{1} \mathrm{G}_{4}$ excitation, we have simplified the situation by considering only two types of sites, but it is clear that actually many sites exist, some of which (corresponding to nearest-neighbor $\mathrm{Tm}^{3+}$ ions for example) may have very short lifetimes. The latter must not be numerous enough to detect their fluorescence after a direct excitation process such as a ${ }^{1} G_{4}$ excitation. However it can be more easily detected when it is a consequence, as in the case of a ${ }^{3} \mathrm{H}_{5}$ excitation, of an up-conversion process, i.e. an energy transfer mechanism concerning nearby $\mathrm{Tm}^{3+}$ ions predominantly.

3.3.2 620-730 nm red emissions. - The excitation of the ${ }^{3} \mathrm{H}_{5}$ level also leads to a red emission; its decay, recorded at $700 \mathrm{~nm}$, consists of two short components (2 and $30 \mu \mathrm{s})$ which can be assigned to the ${ }^{1} \mathrm{G}_{4} \rightarrow{ }^{3} \mathrm{~F}_{4}$ transition.

The excitation of the ${ }^{3} \mathrm{H}_{4}$ level gives rise to a weak red emission (Fig. 10, curve c) which is also due to an up-conversion mechanism. Its time-dependence does not show any risetime, but an exponential decay with a time-constant of $1.45 \mathrm{~ms}$. The emission spectrum between 640 and $670 \mathrm{~nm}$ (Fig. 10, curve c) is the same as that obtained by exciting the ${ }^{3} \mathrm{~F}_{2}$, ${ }^{3} \mathrm{~F}_{3}$ levels at $683 \mathrm{~nm}$ (Fig. 10, curve a). It is attributed to ${ }^{3} \mathrm{~F}_{2},{ }^{3} \mathrm{~F}_{3} \rightarrow{ }^{3} \mathrm{H}_{6}$ and ${ }^{1} \mathrm{G}_{4} \rightarrow{ }^{3} \mathrm{~F}_{4}$ transitions. On the other hand the strongest peak at $695 \mathrm{~nm}$ obtained by exciting the ${ }^{3} \mathrm{~F}_{2},{ }^{3} \mathrm{~F}_{3}$ levels at $683 \mathrm{~nm}$ (Fig. 10a) has completely vanished. This means that the transfers by up-conversion do not involve the particular site in which the ${ }^{3} \mathrm{~F}_{3}$ emission mainly occurs at $695 \mathrm{~nm}$.

Let us now consider the excitation of the ${ }^{3} \mathrm{~F}_{2},{ }^{3} \mathrm{~F}_{3}$ levels, in particular the excitations at 683 and $695 \mathrm{~nm}$, which give rather peculiar results. When the $\mathrm{Tm}^{3+}$ ions are excited at $695 \mathrm{~nm}$ (Fig. 10, curve b), the spectrum is flat between 640 and $670 \mathrm{~nm}$ and shows three weak peaks at 683,695 and $705 \mathrm{~nm}$. The fluorescence decays recorded at $660,667,680,700$ and $710 \mathrm{~nm}$ are identical, exponential with a time-constant of $1.45 \mathrm{~ms}$. On the other hand, an excitation at $683 \mathrm{~nm}$ (Figs. 10a and 11a) leads to an emission spectrum presenting small structures between 640 and $660 \mathrm{~nm}$ and the peak at $695 \mathrm{~nm}$ is strongly enhanced compared with the two satellites at 683 and $705 \mathrm{~nm}$. The decay modes at 650 and $667 \mathrm{~nm}$ are made essentially of a long component with a time-constant of $\sim 2.5 \mathrm{~ms}$ while at 683 and $695 \mathrm{~nm}$, the decays involve two distinct components, a short one with a mean time-constant of about $40 \mu \mathrm{s}$ which may be shared itself into two components $(2$ and $30 \mu \mathrm{s})$, and a long one with a time-constant of $1.55 \mathrm{~ms}$. The contributions of these components to the total red emission were obtained from time-resolved spectroscopy measurements. The time-resolved spectra are shown in figure 11. When the spectrum is resolved at short times after the laser pulse only the emission peak at $695 \mathrm{~nm}$ (curve b) appears. When it is resolved at long times, all the other structures appear 


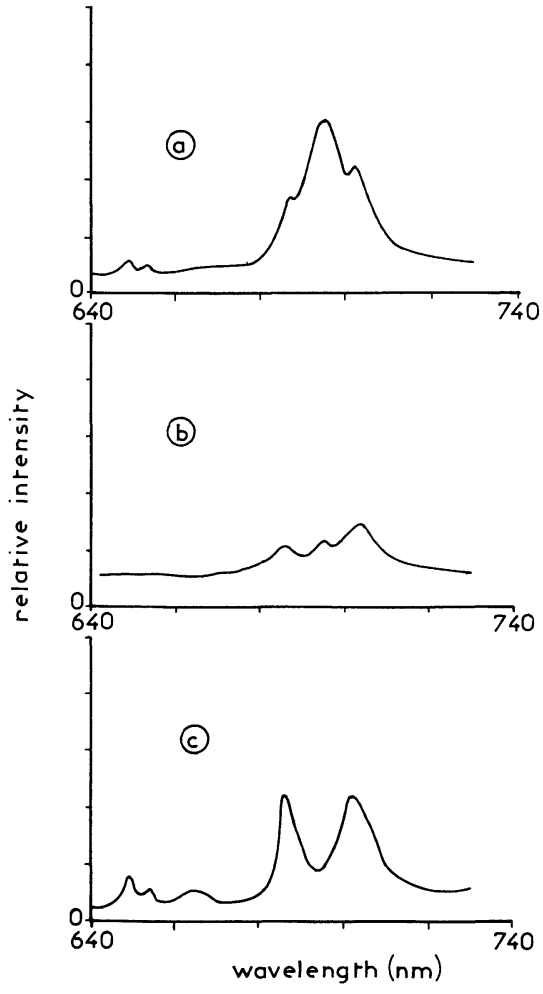

Fig. 10.

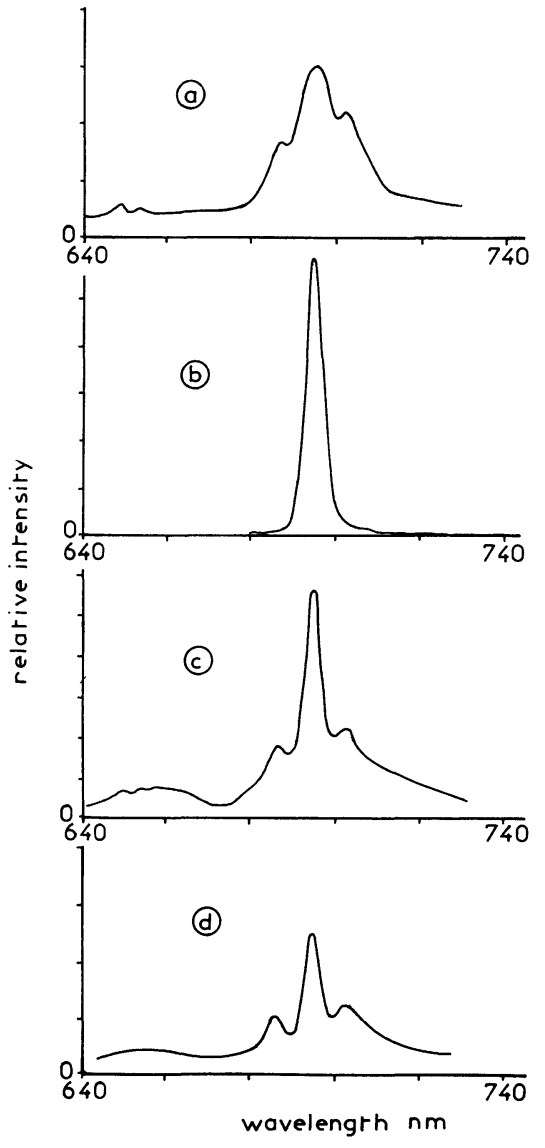

Fig. 11.

Fig. 10. - Red emission spectra obtained at room temperature for a $1 \% \mathrm{Tm}^{3+}$ doped $\mathrm{LiYF}_{4}$ crystal after : a) excitation of the ${ }^{3} \mathrm{~F}_{2},{ }^{3} \mathrm{~F}_{3}$ levels at $683 \mathrm{~nm}$; b) excitation of the ${ }^{3} \mathrm{~F}_{2},{ }^{3} \mathrm{~F}_{3}$ levels at $695 \mathrm{~nm}$; c) excitation of the ${ }^{3} \mathrm{H}_{4}$ level (antiStokes emission).

Fig. 11. - Red fluorescence spectra a) integrated fluorescence spectrum ; b) time-resolved spectrum at short times (gatewidth of signal integration : $100 \mu \mathrm{s}$; delay : $0.5 \mu \mathrm{s}$ ); c) time-resolved spectrum at intermediate times (gatewidth : $500 \mu \mathrm{s}$; delay $200 \mu \mathrm{s}$ ); d) time-resolved spectrum at long times (gatewidth : $400 \mu \mathrm{s}$, delay $1 \mathrm{~ms}$ ).

progressively (curves $\mathrm{c}$ and d), and the intensity of the peak at $695 \mathrm{~nm}$ decreases as the delay increases without yet completely disappearing, since it remains the strongest. As a consequence the fluorescence corresponding to the peak at $695 \mathrm{~nm}$ is mostly short-lived, while the other fluorescences are essentially long-lived fluorescences. The fluorescence decay measured at $683 \mathrm{~nm}$ presents a short component which can be attributed to the influence of the overlapping fluorescence at $695 \mathrm{~nm}$. It comes out from these experimental results that the laser beam at $683 \mathrm{~nm}$ excites two kinds of $\mathrm{Tm}^{3+}$ luminescent centers : some emit a short-lived fluorescence centered at $695 \mathrm{~nm}$ and may be considered as $\mathrm{Tm}^{3+}$ ions at normal sites ; others, emitting a long-lived fluorescence and covering the whole range between 640 and $730 \mathrm{~nm}$, are probably perturbed $\mathrm{Tm}^{3+}$ ions occupying special lattice sites and acting as traps for the red fluorescence. 
We have seen that the red emission between 630 and $680 \mathrm{~nm}$, obtained by exciting the ${ }^{1} \mathrm{G}_{4}$ level, is due to a ${ }^{1} \mathrm{G}_{4} \rightarrow{ }^{3} \mathrm{~F}_{4}$ transition. We also have detected a very weak red emission between 680 and $705 \mathrm{~nm}$. As in the case of the previous excitation, the decay of this fluorescence comprises a short component, stronger at $695 \mathrm{~nm}$ than at $705 \mathrm{~nm}$, and a long one with a time-constant of $1.45 \mathrm{~ms}$. Therefore this residual fluorescence is attributed again to ${ }^{3} \mathrm{~F}_{2},{ }^{3} \mathrm{~F}_{3} \rightarrow{ }^{3} \mathrm{H}_{6}$ transitions within $\mathrm{Tm}^{3+}$ ions in different sites.

3.3.3 ${ }^{1} \mathrm{G}_{4} \rightarrow{ }^{3} \mathrm{H}_{6}$ blue-green anti-Stokes emission. - This fluorescence can be obtained by exciting at energies lower than that of the ${ }^{1} \mathrm{G}_{4}$ emitting level and its decay mode depends on the excitation level. Excitation of ${ }^{3} \mathrm{H}_{5}$ leads to a short-lived fluorescence decay of a few $\mu \mathrm{s}$ followed by a long one of $1.5 \mathrm{~ms}$. Excitation of ${ }^{3} \mathrm{H}_{4}$ gives a decay which is nearly exponential with a time-constant of $1.5 \mathrm{~ms}$. By exciting level ${ }^{3} \mathrm{~F}_{3}$ one observes at $474 \mathrm{~nm}$ a fluorescence decay which consists of two short-lived components with time constants of 2 and $80 \mu$ s and at $478 \mathrm{~nm}$ a decay made of a short- and a long-lived component with time-constants of a few $\mu \mathrm{s}$ and $1.3 \mathrm{~ms}$, respectively. These experimental results reflect very complicated up-conversion processes which would be difficult to interpret very accurately and that we shall not analyse any further.

\section{4. $\mathrm{Tm}^{3+} \rightarrow \mathrm{Ho}^{3+}$ energy transfers.}

Three samples were investigated containing $7 \%$ of $\mathrm{Tm}^{3+}$ ions and $x \%$ of $\mathrm{Ho}^{3+}$ ions $(x=0.5,2$ and 5). The transfer processes were studied in the case of infrared excitation of each of the low-lying levels ${ }^{3} \mathrm{H}_{4}$ and ${ }^{3} \mathrm{~F}_{4}$. The excitation of the $\mathrm{Tm}^{3+}$ ions in the ${ }^{3} \mathrm{H}_{4}$ excited state is particularly important because it corresponds to the emission range of the laser diodes around $795 \mathrm{~nm}$.

4.1 ${ }^{3} \mathrm{~F}_{4} \rightarrow{ }^{5} \mathrm{I}_{7}$ ENERGY TRANSFERS. - These transfers are analysed by directly exciting the ${ }^{3} \mathrm{~F}_{4}$ level in the infrared region around $1.68 \mu \mathrm{m}$ (Fig. 12).

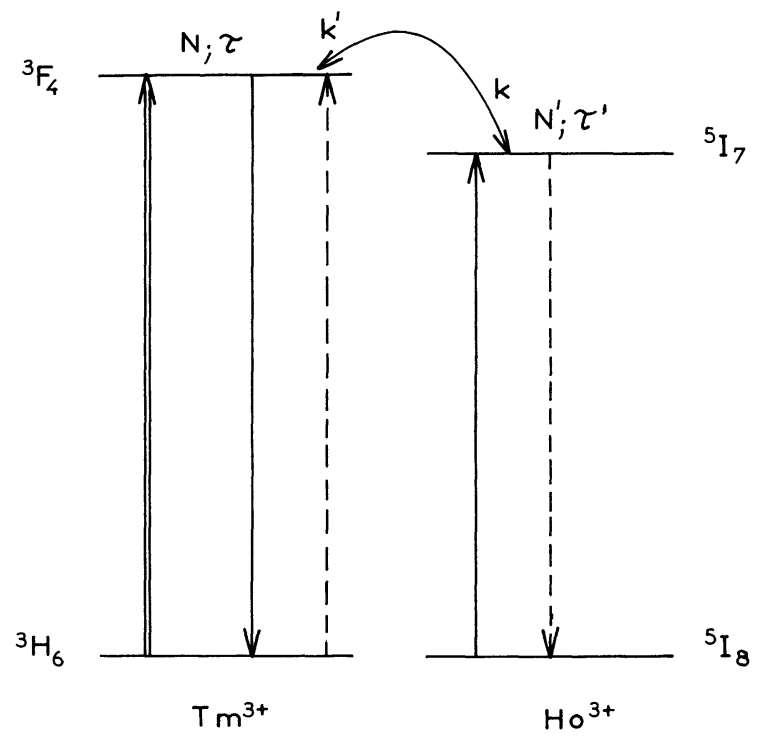

Fig. 12. - Energy transfers ${ }^{3} \mathrm{~F}_{4},{ }^{5} \mathrm{I}_{8} \rightarrow{ }^{3} \mathrm{H}_{6},{ }^{5} \mathrm{I}_{7}$ at room temperature in $\mathrm{LiYF}_{4}: 7 \% \mathrm{Tm}: x \%$ Ho $(x=0.5,2,5)$. 
4.1.1 Transfers at room temperature. - The fluorescence decay of the ${ }^{3} \mathrm{~F}_{4} \rightarrow{ }^{3} \mathrm{H}_{6}$ transition of the $\mathrm{Tm}^{3+}$ ions shows first a very strong and short component of a few tens of $\mu \mathrm{s}$, and then a very long one with a time-constant of $15-19 \mathrm{~ms}$. The time-constants of the two components are so different that it is necessary to use different basetimes to clearly detect them. The time dependence of the fluorescence of the $\mathrm{Ho}^{3+}$ ions corresponding to the ${ }^{5} \mathrm{I}_{7} \rightarrow{ }^{5} \mathrm{I}_{8}$ transition near $2 \mu \mathrm{m}$ presents a short built-up of a few tens of $\mu$, and a long decay identical to the one of the ${ }^{3} \mathrm{~F}_{4}$ fluorescence.

These data are easy to interpret. The short component of the $\mathrm{Tm}^{3+}$ fluorescence decay represents the lifetime of the ${ }^{3} \mathrm{~F}_{4}$ level. Its strong shortening is due to the $\mathrm{Tm}^{3+} \rightarrow \mathrm{Ho}^{3+}$ energy transfers and also to the fast diffusion among the $\mathrm{Tm}^{3+}$ ions, which probably occurs in such concentrated systems $\left(7 \% \mathrm{Tm}^{3+}\right)$. The rapid risetime of the $\mathrm{Ho}^{3+}$ fluorescence corresponds to the feeding time of the ${ }^{5} \mathrm{I}_{7}$ level via this ${ }^{3} \mathrm{~F}_{4} \rightarrow{ }^{5} \mathrm{I}_{7}$ energy transfer, and this population build-up corresponds well to the decay of the ${ }^{3} \mathrm{~F}_{4}$ fluorescence observed at short times. However when the ${ }^{5} \mathrm{I}_{7}$ level is sufficiently populated, ${ }^{5} \mathrm{I}_{7} \rightarrow{ }^{3} \mathrm{~F}_{4}$ phonon-assisted backtransfers can occur and it follows a population equilibrium between both ${ }^{3} \mathrm{~F}_{4}$ and ${ }^{5} \mathbf{I}_{7}$ levels which decay at long times with the same time constant. This is possible at room temperature since the two excited levels are separated by only a few hundreds of wavenumbers. Thus the transfer mechanisms can be described, using the notation indicated in figure 12 , with the following equations :

$$
\begin{gathered}
\dot{N}=-\frac{N}{\tau}-k N+k^{\prime} N^{\prime} \\
\dot{N}^{\prime}=-\frac{N^{\prime}}{\tau^{\prime}}-k^{\prime} N^{\prime}+k N
\end{gathered}
$$

Taking into account the initial conditions

$$
N(0)=N_{0} \text { and } \quad N^{\prime}(0)=0,
$$

the solution of the system is :

$$
\begin{aligned}
N & =\alpha \exp \left(r_{2} t\right)+\beta \exp \left(r_{1} t\right) \\
N^{\prime} & =\alpha^{\prime}\left[\exp \left(r_{1} t\right)-\exp \left(r_{2} t\right)\right]
\end{aligned}
$$

where $\alpha, \beta$ and $\alpha^{\prime}$ are constants and $r_{1}$ and $r_{2}$ are given by :

$$
\begin{aligned}
& r_{1}=\frac{1}{2}\left\{-\left(\frac{1}{\tau}+k+\frac{1}{\tau^{\prime}}+k^{\prime}\right)+\left[\left(\frac{1}{\tau}+k-\left(\frac{1}{\tau^{\prime}}+k^{\prime}\right)\right)^{2}+4 k k^{\prime}\right]^{1 / 2}\right\} \\
& r_{2}=\frac{1}{2}\left\{-\left(\frac{1}{\tau}+k+\frac{1}{\tau^{\prime}}+k^{\prime}\right)-\left[\left(\frac{1}{\tau}+k-\left(\frac{1}{\tau^{\prime}}+k^{\prime}\right)\right)^{2}+4 k k^{\prime}\right]^{1 / 2}\right\}
\end{aligned}
$$

These relations are complex but can be simplified if one assumes :

$$
\frac{1}{\tau} \sim \frac{1}{\tau^{\prime}} \leqslant k^{\prime} \leqslant k
$$

Then relations (19) and (20) become :

$$
\begin{aligned}
& r_{1} \sim-\frac{1}{\tau^{\prime}} \\
& r_{2} \sim-k
\end{aligned}
$$


and according to (21), one finds :

$$
\left|r_{2}\right| \gg\left|r_{1}\right|
$$

in agreement with the experimental observations.

One actually finds experimentally :

$$
\left|r_{2}\right| \sim 10^{5} \mathrm{~s}^{-1}
$$

and

$$
\begin{aligned}
\left|r_{1}\right| & =\frac{10^{3}}{15} \sim 67 \mathrm{~s}^{-1} \text { in } \mathrm{LiYF}_{4}: 7 \% \mathrm{Tm}^{3+}, 0.5 \% \mathrm{Ho}^{3+} \\
& =\frac{10^{3}}{17.3} \sim 58 \mathrm{~s}^{-1} \quad \text { in } \mathrm{LiYF}_{4}: 7 \% \mathrm{Tm}^{3+}, 2 \% \mathrm{Ho}^{3+} \\
& =\frac{10^{3}}{19} \sim 53 \mathrm{~s}^{-1} \quad \text { in } \mathrm{LiYF}_{4}: 7 \% \mathrm{Tm}^{3+}, 5 \% \mathrm{Ho}^{3+}
\end{aligned}
$$

$\frac{1}{\left|r_{1}\right|}$ are interpreted as the values of the $\tau^{\prime}$ lifetimes of ${ }^{5} I_{7}$ in the three samples. It should be noted that the $\tau^{\prime}$ value of $16 \mathrm{~ms}$ obtained in $\mathrm{LiYF}_{4}: 1 \% \mathrm{Ho}^{3+}$ in a previous study [4] agrees well with the trend observed here and indicated in table II. The increase of $\tau^{\prime}$ with the $\mathrm{Ho}^{3+}$ concentration, previously observed in $\mathrm{LiYF}_{4}: 50 \% \mathrm{Er}, x \% \mathrm{Ho}$ [4], is confirmed by the present results. This $\mathrm{Ho}^{3+}$ concentration dependence of the lifetime of the ${ }^{5} \mathrm{I}_{7}$ emitting level is explained by the occurrence of radiative energy transfers among the $\mathrm{Ho}^{3+}$ ions.

Table II. - Time-constants of the ${ }^{5} \mathrm{I}_{7}$ fluorescence decays of $\mathrm{Ho}^{3+}$ ions.

\begin{tabular}{ccccc}
$\tau^{\prime}(\mathrm{ms})$ & 15 & 16 & 17.3 & 19 \\
\hline$x(\% \mathrm{Ho})$ & 0.5 & 1 & 2 & 5
\end{tabular}

4.1.2 Temperature-dependence of the transfers. - An example of the temperature-dependence of the $1.8 \mu \mathrm{m}$ fluorescence decay of the $\mathrm{Tm}^{3+}$ ions in $\left(\mathrm{Tm}^{3+}, \mathrm{Ho}^{3+}\right)$ co-doped $\mathrm{LiYF}_{4}$ is represented in figure 13.

According to our model, a few tens of $\mu \mathrm{s}$ after the excitation, both the ${ }^{3} \mathrm{~F}_{4}$ and ${ }^{5} \mathrm{I}_{7}$ levels decay with the same time-constant $\frac{1}{\left|r_{1}\right|}$ which represents the lifetime $\tau^{\prime}$ of the ${ }^{5} \mathrm{I}_{7}$ fluorescence. The predominance of the ${ }^{5} \mathrm{I}_{7}$ level (which imposes its lifetime to the dynamics) over the ${ }^{3} \mathrm{~F}_{4}$ level is due to the fact that the ${ }^{3} \mathrm{~F}_{4} \rightarrow{ }^{5} \mathrm{I}_{7}$ direct-transfer is more rapid than the ${ }^{5} \mathrm{I}_{7} \rightarrow{ }^{3} \mathrm{~F}_{4}$ back-transfer $\left(k \gg k^{\prime}\right)$ and consequently the $N^{\prime}(t)$ population of ${ }^{5} \mathrm{I}_{7}$ is higher than the $N(t)$ one of ${ }^{3} \mathrm{~F}_{4}$ whatever the temperature and the more as the temperature is low.

The linear temperature-dependence of $\operatorname{Ln}\left(\frac{N}{N^{\prime}}\right)$ with $\frac{1}{T}$ (Fig. 14) confirms the existence of a Boltzmann population equilibrium between the ${ }^{3} \mathrm{~F}_{4}$ and ${ }^{5} \mathrm{I}_{7}$ levels, with an activation energy of about $450 \mathrm{~cm}^{-1}$. This value is in good agreement with the energy mismatch between the two excited states as it can be seen in the right part of figure 14 and is of the same order of magnitude as the maximum phonon frequency in $\mathrm{LiYF}_{4}$ crystal : $380 \mathrm{~cm}^{-1}$. The long-lived component of the ${ }^{3} \mathrm{~F}_{4}$ fluorescence decay resulting from the ${ }^{5} \mathrm{I}_{7} \rightarrow{ }^{3} \mathrm{~F}_{4}$ back-transfers 


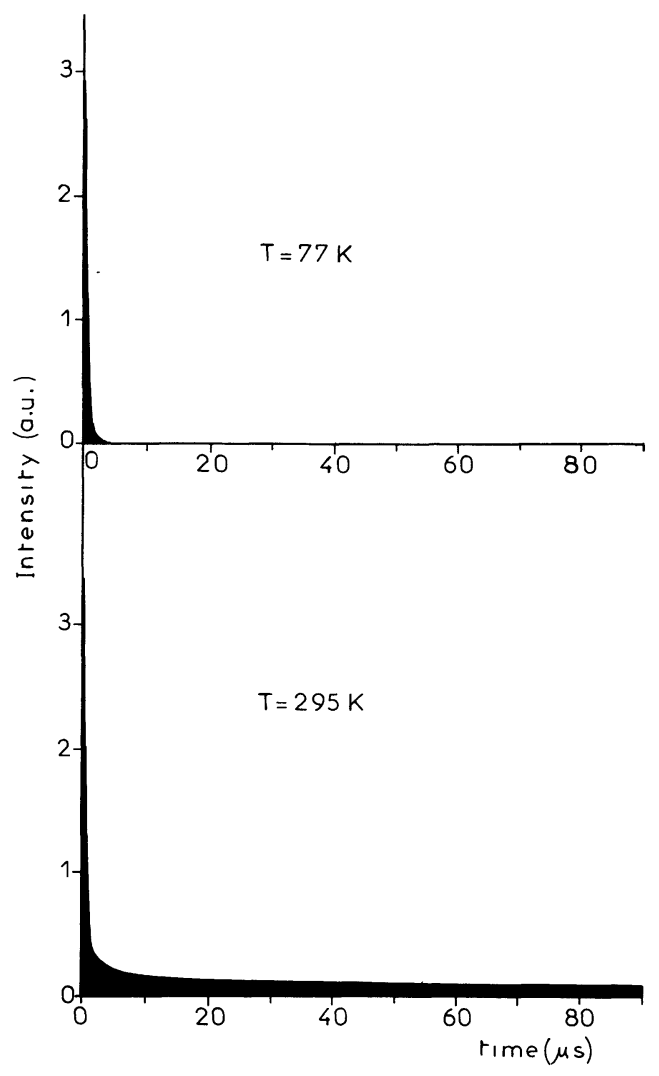

Fig. 13. - Temperature-dependence of the $1.8 \mu \mathrm{m}$ fluorescence decay after excitation of the ${ }^{3} \mathrm{~F}_{4}$ level.

at room temperature vanishes by $T \approx 200 \mathrm{~K}$ and it is completely quenched at liquid nitrogen temperature (Fig. 13).

4.2 $\mathrm{Tm}^{3+} \rightarrow \mathrm{Ho}^{3+}$ ENERGY TRANSFERS IN CASE OF ${ }^{3} \mathrm{H}_{4}$ EXCITATION. - In section 3.2.1 we mentioned that a very efficient cross-relaxation type energy transfer among the $\mathrm{Tm}^{3+}$ ions could be responsible for the $1.45 \mathrm{~ms}$ time-constant observed, in the fluorescence decay of level ${ }^{3} \mathrm{H}_{4}$ as well as in the fluorescence rise of level ${ }^{3} \mathrm{~F}_{4}$, in the singly doped $\mathrm{LiYF}_{4}: 1 \%$ $\mathrm{Tm}^{3}+$ compound after excitation in the ${ }^{3} \mathrm{H}_{4}$ level. This seems to be confirmed in the codoped systems $\mathrm{LiYF}_{4} 7 \% \mathrm{Tm}^{3+}, x \% \mathrm{Ho}^{3+}$ since the decay of the ${ }^{3} \mathrm{H}_{4}$ fluorescence and the rise of the ${ }^{3} \mathrm{~F}_{4}$ fluorescence are now reduced to a few $\mu$ s. This reduced time-constants however can also be attributed, as sketched in figure 15 , by other transfer processes, now between the ${ }^{3} \mathrm{H}_{4}$ level of the $\mathrm{Tm}^{3+}$ ions and the ${ }^{5} \mathrm{I}_{5}$ or ${ }^{5} \mathrm{I}_{4}$ level of the $\mathrm{Ho}^{3+}$ ions and/or by a cross-relaxation process of type : ${ }^{3} \mathrm{H}_{4},{ }^{5} \mathrm{I}_{8} \rightarrow{ }^{3} \mathrm{~F}_{4},{ }^{5} \mathrm{I}_{7}$. In this case the rate equation for the ${ }^{3} \mathrm{H}_{4}$ population density can be written :

$$
\dot{N}=-\frac{N}{\tau^{0}}-k N N_{0}-k^{\prime} N N_{0}^{\prime}
$$

where $k$ and $k^{\prime}$ stand for the transfer constants involved in figure 15 and where $N_{0}$ and $N_{0}^{\prime}$, the ${ }^{3} \mathrm{H}_{6}$ and ${ }^{5} \mathrm{I}_{8}$ population densities, respectively, are assumed to be constant 


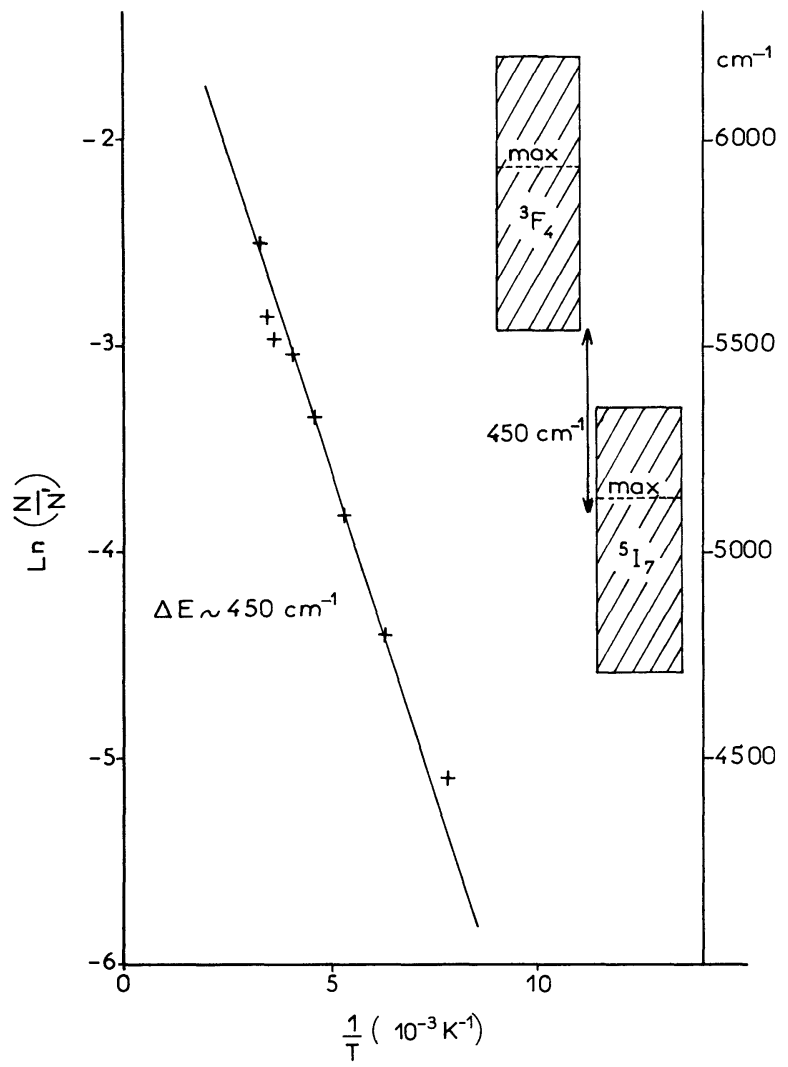

Fig. 14. - Temperature-dependence of the population ratio of the ${ }^{3} \mathrm{~F}_{4}(N)$ and ${ }^{5} \mathrm{I}_{7}\left(N^{\prime}\right)$ energy levels of the $\mathrm{Tm}^{3+}$ and $\mathrm{Ho}^{3+}$ ions, respectively.

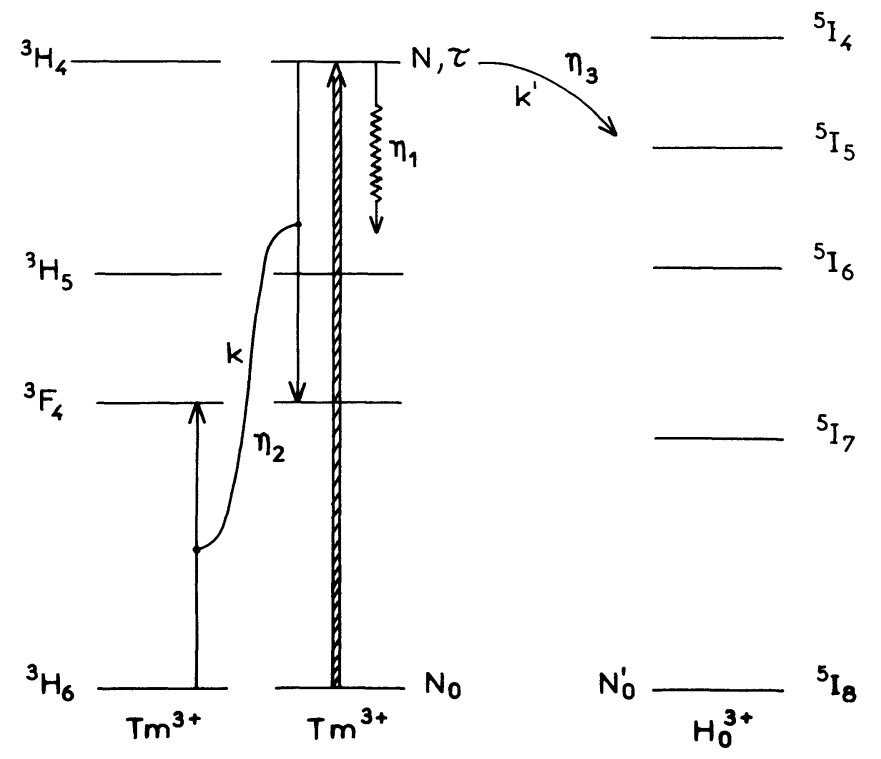

Fig. 15. - The three channels of de-excitation of the $\mathrm{Tm}^{3+}$ ions. 
(weak excitation density). $\tau^{0}$ is the fluorescence lifetime of level ${ }^{3} \mathrm{H}_{4}$ in the absence of transfers. The solution of equation (25) gives rise to an exponential decay with a timeconstant $\tau$ such as :

$$
\frac{1}{\tau}+\frac{1}{\tau^{0}}+k N_{0}+k^{\prime} N_{0}^{\prime}
$$

Instead of studying the ${ }^{3} \mathrm{H}_{4} \rightarrow{ }^{3} \mathrm{H}_{6}$ fluorescence decay, which is difficult to record because the excitation and the fluorescence are in resonance, we have analysed the rise of the ${ }^{3} \mathrm{~F}_{4}$ fluorescence near $1.8 \mu \mathrm{m}$. This fast fluorescence rise, which is interpreted as the lifetime $\tau$ of level ${ }^{3} \mathrm{H}_{4}$ (Tab. III) and the fast decay which follows at short times are strongly dependent on the $\mathrm{Ho}^{3+}$ concentration, and this is indicative of the $\mathrm{Tm}^{3+} \rightarrow \mathrm{Ho}^{3+}$ energy transfers from the ${ }^{3} \mathrm{H}_{4}$ as well as from the ${ }^{3} \mathrm{~F}_{4}$ energy levels as shown in figures 12 and 15 .

Table III. - Lifetimes of ${ }^{3} \mathrm{H}_{4}$ level and quantum efficiencies of the 3 different channels of deexcitation.

\begin{tabular}{ccccc}
\hline$x(\% \mathrm{Ho})$ & 0 & 0.5 & 2 & 5 \\
\hline$\tau(\mu \mathrm{s})$ & 12.5 & 6.5 & 3 & 1.2 \\
\hline$\eta_{1}(\%)$ & 0.33 & 0.17 & 0.08 & 0.03 \\
\hline$\eta_{2}(\%)$ & 99.67 & 51.83 & 23.92 & 9.57 \\
\hline$\eta_{3}(\%)$ & 0 & 48.00 & 76.00 & 90.40 \\
\hline
\end{tabular}

The short-time as well as the long-time fluorescence decays of level ${ }^{3} \mathrm{~F}_{4}$ vary with the $\mathrm{Ho}^{3+}$ concentration in the same way and for the same reasons as for a ${ }^{3} \mathrm{~F}_{4}$ excitation (see Sect. 4.1.1). The experimental variation of $\frac{1}{\tau}$ with the $N_{0}^{\prime}{ }^{5} \mathrm{I}_{8}$ ground state population density (proportional to the $x \mathrm{Ho}^{3+}$ concentration) (Fig. 16) can be fitted with a straight line according to equation (26). If we take $\tau^{0}=3.8 \mathrm{~ms}$, which is the experimental value of the ${ }^{3} \mathrm{H}_{4}$ lifetime measured in a very lightly doped $\mathrm{LiYF}_{4}: \mathrm{Tm}^{3+}$ sample [15], it is possible to deduce $k N_{0}$ knowing the extrapolated value of $\tau$ at $N_{0}^{\prime}=0$.

Finally, the quantum efficiencies of the three main mechanisms involved in the ${ }^{3} \mathrm{H}_{4}$ excited state dynamics, namely the Tm intra-center de-excitation, the $\mathrm{Tm}^{3+} \rightarrow \mathrm{Tm}^{3+}$ cross-relaxation and the $\mathrm{Tm}^{3+} \rightarrow \mathrm{Ho}^{3+}$ direct energy transfer, can be evaluated by using the relations :

$$
\begin{aligned}
& \eta_{1}=\frac{\tau}{\tau_{0}} \\
& \eta_{2}=\tau \times k N_{0} \\
& \eta_{3}=1-\eta_{1}-\eta_{2}
\end{aligned}
$$

The calculated values are gathered in table III. As expected, $\eta_{1}$ is very weak whatever the $\mathrm{Ho}^{3+}$ concentration. In a singly doped compound with $7 \% \mathrm{Tm}^{3+}$ and no $\mathrm{Ho}^{3+}$ the dynamics would be completely governed by the $\mathrm{Tm}^{3+} \rightarrow \mathrm{Tm}^{3+}$ cross relaxation process $\left(\eta_{2}\right)$. In the 


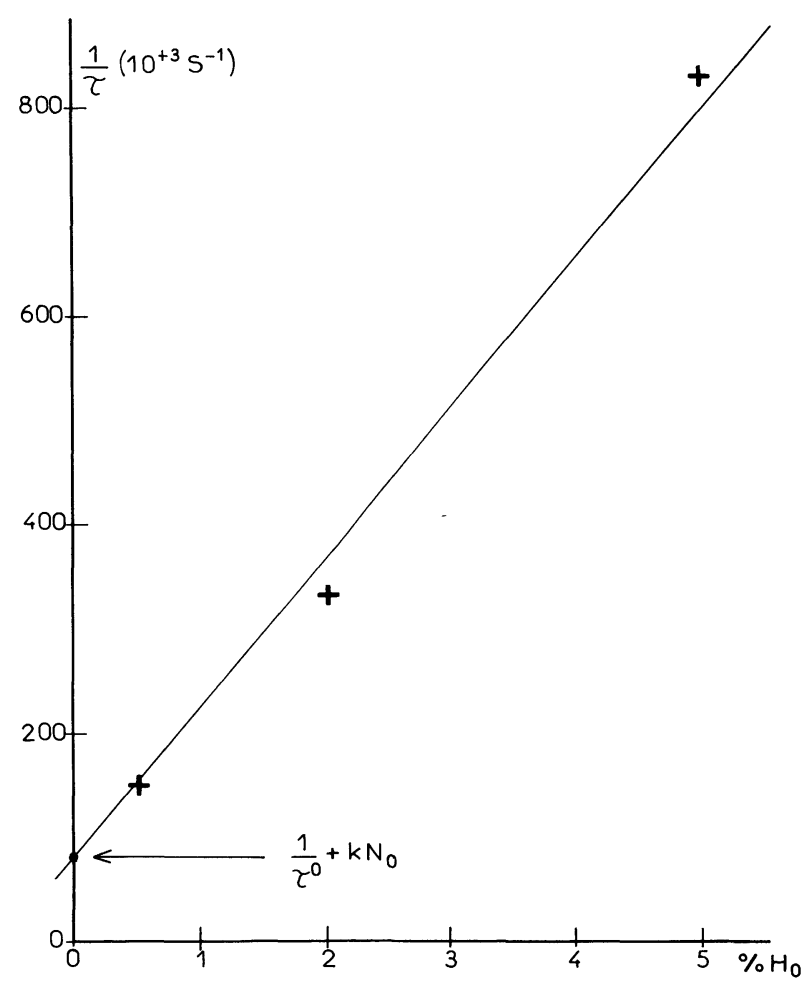

Fig. 16. - Inverse time-constant of the ${ }^{3} \mathrm{~F}_{4}$ fluorescence rise following a ${ }^{3} \mathrm{H}_{4}$ excitation of the $\mathrm{LiYF}_{4}: 7 \% \mathrm{Tm}^{3+}, x \% \mathrm{Ho}^{3+}$ compounds.

codoped systems this process competes with the $\mathrm{Tm}^{3+} \rightarrow \mathrm{Ho}^{3+}$ transfer processes $\eta_{3}$ which become highly predominant at high $\mathrm{Ho}^{3+}$ concentrations.

\section{Summary and concluding remarks.}

The study of the excited-state dynamics of the $\mathrm{Tm}^{3+}$ ions in a $1 \% \mathrm{Tm}^{3+}$ doped crystal of $\mathrm{LiYF}_{4}$ leads to very particular results. First it shows the existence of numerous coincidences between the various fluorescences that only a careful examination, made in different excitation conditions, allow to distinguish. In addition, the whole dynamics can be interpreted by taking into account the possibility of a $\mathrm{Tm}^{3+}$ ion to have other $\mathrm{Tm}^{3+}$ ions in closeby positions or to be isolated. The former, that Barthem and Buisson [16] have treated in terms of paired-ions, seem to be the main ones that one should invoke to explain the various crossrelaxation and up-conversion processes observed for certain excitations.

Knowing these results, the energy transfer processes in the systems doped with $7 \%$ $\mathrm{Tm}^{3+}$ and $x \% \mathrm{Ho}^{3+}(x=0.5,2,5)$ are studied in two cases of $\mathrm{Tm}^{3+}$ excitation : (i) excitation of level ${ }^{3} \mathrm{H}_{4}$ for it is of particular interest for diode-pumping purpose, (ii) excitation of level ${ }^{3} \mathrm{~F}_{4}$ since it is the excited level which transfers the best its energy to the ${ }^{5} \mathrm{I}_{7}$ level of the $\mathrm{Ho}^{3+}$ ions responsible for the $2 \mu \mathrm{m}$ laser transition.

The data show very efficient, within a few $\mu \mathrm{s}$, cross relaxation type $\mathrm{Tm}^{3+} \rightarrow \mathrm{Tm}^{3+}$ and direct $\mathrm{Tm}^{3+} \rightarrow \mathrm{Ho}^{3+}$ energy transfers followed by diffusion among the $\mathrm{Tm}^{3+}$ ions and trapping by the $\mathrm{Ho}^{3+}$ ions within a few tens of $\mu$ s, the latter being strongly influenced, on a longer time scale, by temperature-induced $\mathrm{Ho}^{3+} \rightarrow \mathrm{Tm}^{3+}$ back transfers above about $200 \mathrm{~K}$. 


\section{References}

[1] Chicklis E. P., Naiman C. S., Folweiler R. C., Gabbe D. R., Jenssen H. P. and Linz A., Appl. Phys. Lett. 19 (1971) 119.

[2] Lotem H., Kalisky Y., Kagan J. and Sagie D., IEEE J. Quant. Elect. 24 (1988) 1193.

[3] Kintz G., Esterowitz L. and Allen R., Tunable Solid State Lasers, Tech. Dig. Ser. 20 (1987) 20.

[4] Rubin J., Brenier A., Moncorge R. and Pedrini C., J. Phys. 48 (1987) 1761.

[5] Moine B., Brenier A. and Pedrini C., IEEE J. Quant. Electron. 25 (1989) 88.

[6] Varsanyi F. and Dieke G. H., Phys. Rev. Lett. 7 (1961) 442.

[7] Auzel F., C. R. Acad. Sci. Paris 262 (1966) 1016.

[8] Ovsyankin V. V. and Feofilov P. P., Sov. Phys. Lett. 4 (1966) 317.

[9] Johnson L. F., Guggenheim H. J., Rich J. C. and Ostermayer F. W., J. Appl. Phys. 43 (1972) 1125.

[10] Auzel F., Proc. IEEE GI (1973) 758.

[11] Wright J. C., Topics in Applied Physics, Eds F. K. Fong (Springer, New York) Vol. 15 (1976) p. 239.

[12] Rubin J., Brenier A., Moncorge R. and Pedrini C., J. Lumin. 36 (1986) 39.

[13] Moncorge R. and GefFraye F., private communication.

see also Moncorge R., Boulon G., Vivien D., Lejus A. M., Collongues R., Djevahirdian V. and K. and CAGNARD R., IEEE J. Quant. Elect. 24 (1988) 1049.

[14] Huang S., Lai S. T., Lou L., Jia W. and Yen W. M., Phys. Rev. B 24 (1981) 59.

[15] BARTHEM R. B., Doctoral thesis (Grenoble, France) June 1987.

[16] BARThem R. B. and Buisson R., J. Lumin. 40-41 (1988) 637. 